\title{
PROJETO INCUTEC: UMA EXPERIÊNCIA DE PRÁTICA INTEGRADORA PARA O CURSO TÉCNICO DE ADMINISTRAÇÃO DO IFMA CAMPUS BURITICUPU
}

\author{
C. H. BONFIM' e C. M. R. SILVA ${ }^{2}$ \\ Instituto Federal do Maranhão \\ cristiani.bonfim@ifma.edu.br ${ }^{1}$, camila.rodrigues@ifma.edu.br ${ }^{2}$
}

Artigo submetido em fevereiro/2014 e aceito em março/2014

\section{RESUMO}

Análise da experiência do projeto de extensão Incubadora de Serviços como Instrumento de Geração de Emprego e Renda (INCUTEC) e suas contribuições para o Curso Técnico em Administração do Instituto Federal do Maranhão (IFMA) Campus Buriticupu. Demonstra a relevância do projeto enquanto prática integradora, para tanto, utilizou-se da combinação de pesquisa bibliográfica, documental e de campo, tendo como instrumento de coleta de dados o questionário aplicado à coordenadora do projeto, aos docentes e discentes envolvidos. Apresenta o projeto INCUTEC em seus aspectos históricos e conceituais e posteriormente destaca sua contribuição para o curso Técnico em Administração do IFMA Campus Buriticupu. Ressalta a importância deste projeto como uma experiência viável enquanto prática integradora, por possibilitar a indissociabilidade entre educação geral e educação profissional, bem como, a intervenção com a realidade local.

PALAVRAS-CHAVE: Educação Profissional, Ensino Médio, Projeto INCUTEC.

\section{INCUTEC PROJECT: AN EXPERIENCE OF INCLUSIVE PRACTICE FOR TRAVEL MANAGEMENT OF TECHNICAL CAMPUS IFMA BURITICUPU}

\begin{abstract}
Analysis of project experience of Incubator Services as an Instrument of Extension of Employment and Income Generation (INCUTEC) and their contributions to the Technical Campus Buriticupu Course Administration Federal Institute of Maranhao (IFMA). Demonstrates the relevance of the project while integrating practice, therefore, we used the combination of bibliographical, documentary research and field, and as a tool for data collection questionnaire applied to the project
\end{abstract}

coordinator, the students and faculty involved. Displays INCUTEC project in its historical and conceptual aspects and then highlighting their contribution to the Technical Administration course IFMA Campus Buriticupu. Underscores the importance of this project as a viable practical experience as integrator by allowing the inseparability between general education and vocational education, as well as the intervention with the local reality.

KEYWORDS: Professional Education, Secondary Education, INCUTEC Project. 


\section{INTRODUÇÃO}

A educação vem historicamente sofrendo as influências da sociedade capitalista e suas mudanças, desde a revolução industrial, fordismo/taylorismo até a acumulação flexível, atualmente em vigor. Não é raro perceber na educação as mesmas exigências do mercado de trabalho, em especial no ensino médio, já que ao final deste período é quando normalmente, inicia-se a entrada no mercado de trabalho. É justamente neste período e, de forma intencional, que o investimento em educação profissional, começa a ser mais enfatizado por parte do poder público, influenciado pelas organizações internacionais, como iniciativa para atender o mercado de trabalho e as mudanças constantes.

O aumento na oferta da educação profissional no ensino médio é considerável na ultima década, mais precisamente, após o Decreto no 5.154/2004 que revoga o Decreto 2.208/1997 e estabelece a articulação entre ensino médio e técnico profissional de nível médio de forma integrada, bem como subsequente e concomitante. A educação profissional no Brasil foi intensificada após o Decreto 5.154/2004 quando se iniciou o aumento na oferta destes cursos, tanto nas escolas públicas estaduais quanto nas federais.

O Maranhão é um dos estados mais atingidos por este processo de expansão da rede federal de educação profissional, que iniciou em 2006 no estado e atualmente contempla 17 cidades, com 19 campi. Um dos municípios abrangidos por esta expansão é o de Buriticupu, com cerca de 66 mil habitantes, conforme dados do IBGE (2010). Nele, o Instituto Federal de Educação, Ciência e Tecnologia do Maranhão (IFMA) foi implantado no ano de 2007 com dois cursos técnicos e hoje já oferece dez cursos (ver tabela 1), a saber:

Tabela 1 - Cursos ofertados pelo IFMA Campus Buriticupu

\begin{tabular}{|c|c|c|}
\hline EIXO TECNOLÓGICO & CURSO & FORMA \\
\hline \multirow{5}{*}{ Gestão e Negócios } & Administração & Integrado \\
\hline & Vendas & Integrado \\
\hline & Administração & Subsequente \\
\hline & Contabilidade & Subsequente \\
\hline & Cooperativismo & Subsequente \\
\hline Ambiente e Saúde & Meio Ambiente & Integrado \\
\hline \multirow{2}{*}{ Recursos Naturais } & Agronegócio & Integrado \\
\hline & Agroecologia & Subsequente \\
\hline Informação e Comunicação & Informática & Integrado \\
\hline Controle e Processos & Eletrotécnica & Integrado \\
\hline $\begin{array}{c}\text { Desenvolvimento Educacional } \\
\text { e Social }\end{array}$ & Secretaria Escolar & Integrado \\
\hline
\end{tabular}

Conforme aponta a tabela acima, observa-se que a maioria dos cursos ofertados pelo IFMA Campus Buriticupu são na forma integrada, a fim de atender o artigo 7으 inciso I e o artigo 8으 da Lei 
Federal no 11.892 de 29 de dezembro de 2008, que determina como um dos objetivos dos Institutos Federais a oferta de 50\%, no mínimo, de cursos técnicos integrados ao ensino médio.

O Ministério da Educação determina o uso do Catálogo Nacional de Cursos Técnicos para definir a oferta de cursos nos Institutos Federais, dividido por eixos. O catálogo mostra os cursos possíveis, área de atuação, bem como, a carga horária mínima, um resumo bem simplificado de cada curso, cabendo à instituição de ensino dar riqueza de formação ao curso ofertado, com mérito aos parágrafos II e III do decreto no 5.154/2008 que abre espaço para o respeito às normas de cada sistema de ensino e às exigências dos estabelecimentos de ensino, conforme sua proposta pedagógica. Este é um fator essencial, para que o ensino médio integrado atinja o mínimo da qualidade educacional necessária, para a qual é imprescindível a autonomia da instituição, bem como, o respeito às peculiaridades do contexto local.

Dentre os eixos tecnológicos contemplados no IFMA Campus Buriticupu está o de Gestão e Negócios, onde se encontra o maior número de cursos ofertados, sendo estes: administração, contabilidade, cooperativismo e vendas.

Este trabalho restringe-se ao curso técnico profissional de administração integrado ao ensino médio, que tem sido um dos mais procurados pelos alunos que fazem o seletivo do IFMA Campus Buriticupu. Conforme o projeto de curso aprovado, o objetivo desta instituição é formar o profissional capaz de atender as novas demandas geradas pelo mercado de trabalho, com espírito empreendedor capaz de planejar, organizar, liderar e controlar as novas incumbências do mundo organizacional, não mais a formação para um posto de trabalho que prepare o homem "executor de tarefas", e sim a de um técnico em administração profissional pensante e flexível no mundo das tecnologias avançadas e processos de gestão que sofrem constantemente com as mudanças que se fazem presentes nesse contexto, desenvolvendo habilidades e comportamentos em consonância com as mudanças e sujeito capaz do exercício da cidadania.

O Ensino Médio integrado torna-se relevante desde que a formação geral esteja articulada com a educação técnica profissional, segundo Kuenzer (2010, p.865), "não se opõem, mas contrariamente, se integram e, nesse sentido, asseguram melhor qualidade, principalmente para os que vivem do trabalho". Assim, percebe-se uma mesma linha de pensamento entre o projeto do curso técnico profissional de administração integrado ao ensino médio e a concepção de Kuenzer no que tange a integrar de forma qualitativa a educação geral e profissional.

Mesmo explícito no projeto de curso as intencionalidades desta instituição supracitada, há sempre que se tomar o cuidado em perceber a diferença entre os documentos escritos e a operacionalização e gestão destes, ou seja, as ocorrências diárias vivenciadas. Um curso técnico profissional exige, para uma melhor compreensão, práticas que possibilitem a conexão com a teoria, assim, nota-se que em todo curso técnico profissional integrado ao ensino médio, um dos maiores desafios é promover a prática integradora, que possibilite a interação entre teoria e prática, pois segundo Araujo e Melo (2012, p. 519) se sabe que:

De fato, a teoria e a prática não existem isoladamente, uma não existe sem a outra. Na realidade, uma depende da outra e exercem uma influência mútua. Quando a teoria se sobressai tende a posições idealistas, e uma prática sem teoria gera o ativismo, onde não se sabe nem o que pratica. 
Portanto, para a formação integral dos discentes de cursos técnicos profissionais é relevante que a teoria e prática sejam indissociáveis. A partir deste pressuposto, observou-se a iniciativa de uma experiência de prática integradora, através de um projeto de extensão intitulado INCUTEC, o qual é desenvolvido no IFMA Campus Buriticupu com alunos do Curso Técnico em Administração integrado ao Ensino Médio, sob coordenação da professora Esp. Andréa Lima Barros.

Durante três meses acompanhou-se as principais atividades do referido projeto, bem como o envolvimento e compromisso dos alunos com as ações propostas pelo mesmo. Desta forma, o presente artigo pretende mostrar a relevância do projeto INCUTEC como exemplo de prática integradora na educação profissional do curso técnico em administração do IFMA Campus Buriticupu.

A pesquisa é de natureza qualitativa baseada na combinação de pesquisa bibliográfica, documental e de campo. Destaca-se neste trabalho a contribuição de Frigotto (2010) no que tange ao trabalho reduzido á mercadoria força de trabalho, Ciavatta (2010) no que concerne a discussão acerca da concepção do trabalho como princípio educativo no ensino médio integrado e Kuenzer e Ramos (2010) que ressaltam a importância da articulação entre formação geral e educação técnica profissional no ensino médio integrado. Araújo e Melo (2012) também contribuíram com a importância da relação teoria e prática.

Para a pesquisa documental, analisou-se o projeto do curso Técnico em Administração integrado ao ensino médio do IFMA Campus Buriticupu. Outros documentos importantes que também foram analisados são o projeto INCUTEC, após aprovação em edital, ora institucionalizado e o relatório final apresentado após estes três meses de atividades.

Como instrumento para a pesquisa de campo, utilizou-se a coleta de dados, buscando responder a todas as indagações mediante aplicação de questionário com perguntas abertas à coordenadora do projeto, aos professores da área de administração e aos discentes envolvidos.

Diante do exposto, abordar-se-á os elementos históricos e conceituais do projeto INCUTEC, destacando a importância da extensão para a formação profissional, a iniciativa de desenvolver na prática os conhecimentos teóricos apresentados em sala de aula e a oportunidade de conhecer melhor a realidade do mercado de trabalho local.

\section{PROJETO INCUTEC: ASPECTOS HISTÓRICOS E CONCEITUAIS}

Conforme observamos anteriormente, a educação profissional surge como forma de contribuir para o desenvolvimento econômico nacional, mas também para fortalecer o processo de inserção cidadã dos brasileiros.

No Maranhão, mais especificamente na cidade de Buriticupu, o Instituto Federal de Educação, Ciência e Tecnologia do Maranhão - IFMA vem qualificando e formando cidadãos capazes de atuarem no mundo do trabalho de maneira crítica, com o objetivo de que os mesmos possam transformar e desenvolver sua região. Nessa instituição oportuniza-se aos alunos tanto educação geral como profissionalizante, integrando assim conhecimentos essenciais para formação de seus discentes. 
Assim como os demais Institutos Federais de Educação Profissional, o IFMA trabalha com ensino, pesquisa e extensão, e segundo o art. 7ํinciso IV da Lei № 11.892 de 29 de dezembro de 2008, é um dos objetivos dos Institutos Federais:

Desenvolver atividades de extensão de acordo com os princípios e finalidades da educação profissional e tecnológica, em articulação com o mundo do trabalho e os segmentos sociais, e com ênfase na produção, desenvolvimento e difusão de conhecimentos científicos e tecnológicos.

Projetos de extensão são de grande relevância para formação de pessoas em qualquer área de atuação profissional, pois os mesmos buscam tanto mostrar à sociedade os conhecimentos adquiridos pelos alunos no ambiente educacional quanto fazer com que o aluno perceba a importância de verificar na prática o que aprendeu na teoria em sala de aula, sendo assim esses projetos excelentes ações de práticas integradoras.

O IFMA oportuniza aos servidores o desenvolvimento de projetos de extensão, exemplo disso, está no edital lançado em 2012, oferecendo recursos financeiros para implantação dos mesmos nos diversos campi desta instituição. Nesse contexto que a docente Andrea Lima Barros, graduada e especialista em Administração, decidiu implantar no IFMA Campus Buriticupu o projeto INCUTEC.

Em leitura feita ao projeto INCUTEC, soube-se que o mesmo objetiva disponibilizar aos alunos a possibilidade de conhecer o mercado onde irão atuar, oportunizar intercambio entre Instituto de ensino e mercado formal, favorecer ao meio ambiente organizacional da cidade de Buriticupu o conhecimento dos ramos e profissionais que o IFMA injeta no mercado local, além de possibilitar o acesso direto dos profissionais recém-formados ao mercado após a conclusão dos cursos técnicos ou tecnológicos. Segundo Barros (2012), autora do projeto,

É inegável a importância da disponibilização de espaços como esses para incremento das noções inovadoras do empreendedorismo em todos os espaços laborais, o fortalecimento da cultura do desenvolvimento local e sustentável e da valorização da mão de obra local qualificada, bem como ainda oportunizar a inserção desses jovens no mercado de trabalho formal e informal.

O projeto INCUTEC tem como público alvo discentes que ainda não tiveram acesso ao mundo do trabalho e que terão a oportunidade de conhecer, diagnosticar e atender demandas de empresas, associações, entidades organizadas e demais formas de organizações sociais representativas da sociedade civil.

Diante disso, os alunos estarão relacionando a teoria que viram em sala de aula com a prática vivenciada na realidade local, podendo assim utilizar conhecimentos tanto da educação geral que lhes são oportunizados em sua formação quanto conhecimentos específicos de sua área, no caso em estudo a área de administração.

$\mathrm{Na}$ formação do ensino médio integrado ao ensino técnico Ciavatta (2010, p.84) vem enfocar que "a educação geral se torne parte inseparável da educação profissional em todos os campos onde se dá a preparação para o trabalho". 
Nesse sentido, a idealizadora do projeto INCUTEC, professora Andrea Lima Barros, vem proporcionar aos alunos participantes do projeto um estudo prático sobre as teorias tanto da educação geral quanto profissional repassada aos discentes no ambiente escolar.

\section{O PROJETO INCUTEC E SUA CONTRIBUIÇÃO PARA O CURSO TÉCNICO EM ADMINISTRAÇÃO DO IFMA - CAMPUS BURITICUPU}

Conforme citado anteriormente, no ano de 2012 foi ofertada ao IFMA Campus Buriticupu a oportunidade, por meio de edital, aos servidores do referido campus de trabalharem com projetos de extensão juntamente com alunos. Diante disso, a docente da área de administração Andrea Lima Barros desse campus decidiu concorrer a uma vaga do edital escrevendo o Projeto Incubadora de Serviços como Instrumento de Geração de Emprego e Renda INCUTEC, que foi aprovado.

Esse projeto tem como objetivos oportunizar o intercambio entre Instituto de ensino e mercado formal, favorecendo ao meio ambiente organizacional de Buriticupu o conhecimento dos ramos e profissionais que o IFMA injeta no mercado local além de disponibilizar aos alunos a possibilidade de conhecer o mercado onde irão atuar e possibilitar acesso direto dos profissionais recém-formados ao mercado após a conclusão dos cursos técnicos ou tecnológicos.

Para selecionar a equipe executora da primeira versão desse projeto, a docente Andrea Barros levou em consideração os critérios de disponibilidade, tempo de curso e observância de paridade de gênero. Dentre as contempladas estavam dez discentes as quais, na época, cursavam o 1 ㅇ e 3 을 ano do ensino médio integrado ao curso técnico em administração.

Após este processo de seleção, a coordenadora do projeto orientou as alunas sobre como proceder nos diagnósticos e revezamento das visitas técnicas e elaborou com as mesmas o calendário de atividades, visando o cumprimento de metas para que o projeto fosse executado em tempo hábil. A foto 1 ilustra esse momento de orientação dado as discentes antes da pesquisa de campo.

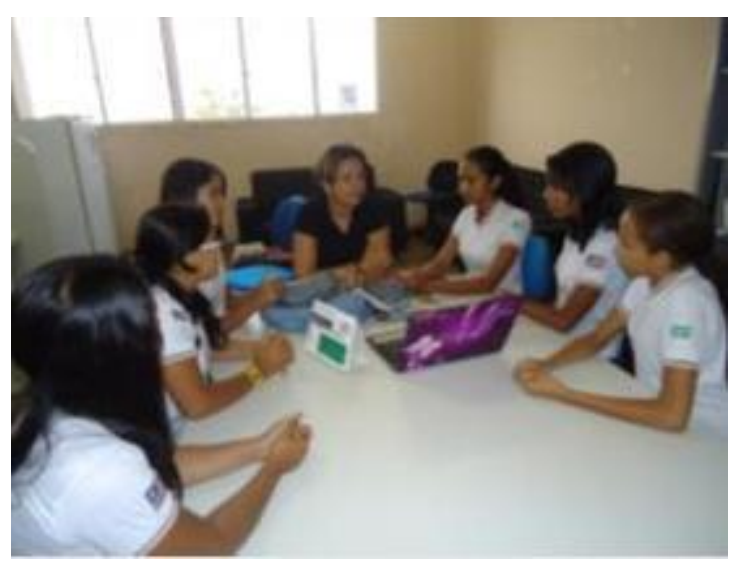

Foto 1: Orientação as alunas do projeto INCUTEC (2012)

Em seguida as alunas realizaram visitas técnicas as empresas da cidade de Buriticupu-MA com o intuito de obter dados das mesmas para assim poderem construir o perfil empresarial da localidade. Nessa ocasião, as discentes aplicaram questionário aberto aos empresários, com perguntas que captassem as informações necessárias sobre as empresas visitadas, seu quadro 
funcional e suas políticas de absorção de mão de obra. A foto 2 ilustrada abaixo mostra as alunas indo a pesquisa de campo.

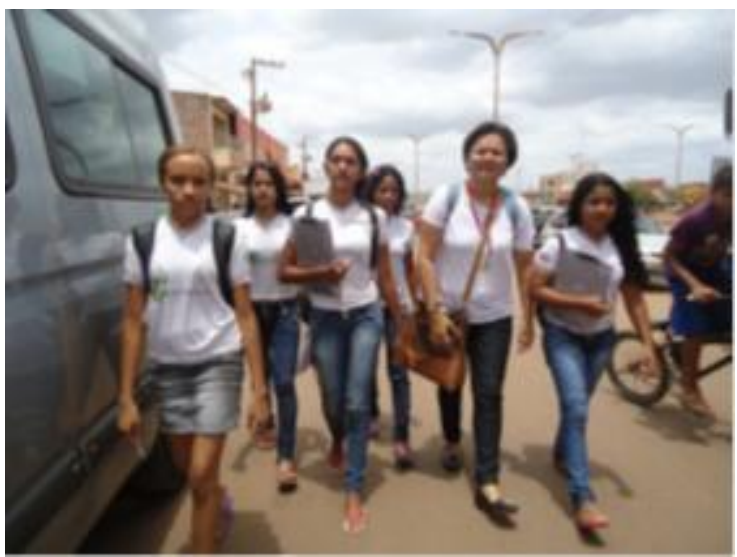

Foto 2: Pesquisa de campo/visita técnica

Depois de observarem a realidade local das empresas e de coletarem os dados em visita técnica, foi proporcionado as discentes discussões em mesas redondas com professores e técnicos do IFMA Campus Buriticupu, onde estas socializaram as experiências vivenciadas e os dados coletados. Nesse momento, as alunas trocaram informações e experiências diversas acerca dos dados levantados sobre cada empresa visitada, conforme vemos nas fotos 3 e 4 .

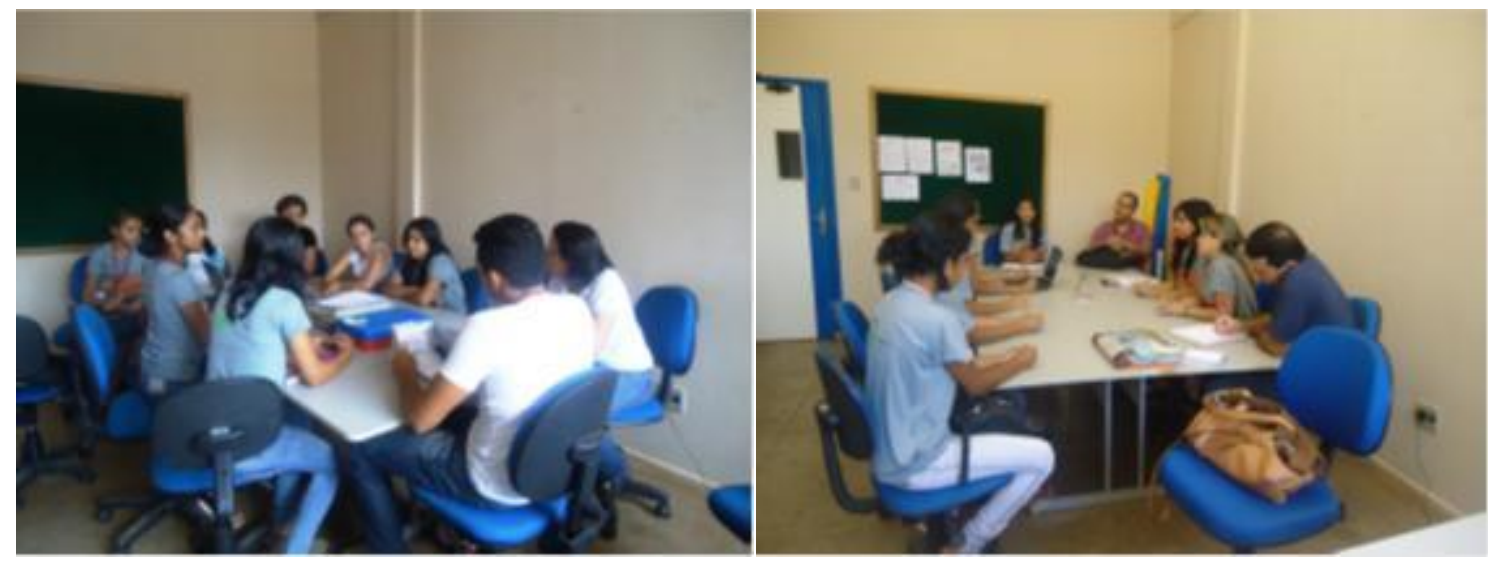

Fotos 3 e 4: Mesa Redonda

Para melhor entendimento do projeto, além de observá-lo durante os três meses de seu desenvolvimento, teve-se acesso aos documentos pertinentes ao mesmo como o projeto escrito que foi submetido ao edital e o projeto do curso técnico de administração integrado ao ensino médio do IFMA Campus Buriticupu. Aplicou-se ainda questionários com as alunas e coordenadora do INCUTEC como também com os professores das disciplinas da área de administração das turmas das discentes participantes.

Diante deste estudo percebeu-se a relevância desse projeto enquanto ação integradora no curso técnico de administração integrado ao ensino médio do IFMA Campus Buriticupu, pois notase a percepção que tanto a instituição quanto a coordenadora do projeto tem em relação à necessidade de integração indissociável entre educação geral e profissional e também a teoria da prática.

No questionário aplicado a coordenadora do projeto, foram feitas indagações a respeito de como surgiu a ideia do projeto INCUTEC, qual o objetivo deste projeto e se, na concepção da 
coordenadora, eles foram alcançados, se houve percepção de mudanças na formação das alunas envolvidas e quais os componentes curriculares diretamente necessários para desenvolver este projeto.

Conforme as respostas obtidas através do questionário, a ideia inicial do projeto surgiu a partir do olhar nas potencialidades locais e analisando como colaborar na relação sociedade e escola. Objetivando favorecer ao meio ambiente organizacional de Buriticupu o conhecimento dos ramos e profissionais formados pelo IFMA, bem como, disponibilizar aos alunos a possibilidade de conhecer o mercado onde irão atuar, com acesso direto dos profissionais recém-formados. A autora acredita que os objetivos foram atingidos parcialmente, pois o projeto ainda permanece em execução.

Nota-se nas respostas dadas pela coordenadora do projeto a intenção de atuar na mudança da realidade, pois quando esta busca as "potencialidades locais" e ainda, se refere a "colaborar na relação sociedade e escola", demonstra uma preocupação com função social da escola, com a formação profissional dos alunos e ainda, pode-se dizer, com a melhoria da realidade local.

Analisando ainda o questionário aplicado a coordenadora do projeto, soube-se que as disciplinas em destaque na tabela 2 foram primordiais para o embasamento teórico inicial do que as discentes vivenciaram na prática, desde o planejamento até as visitas e diagnósticos dados sobre as empresas.

Tabela 2 - Disciplinas do Curso Técnico em Administração do IFMA Campus Buriticupu

\begin{tabular}{|c|c|c|}
\hline PARTES & ÁREA & DISCIPLINA \\
\hline \multirow{13}{*}{ Base nacional comum } & \multirow{4}{*}{$\begin{array}{l}\text { Linguagem, códigos e } \\
\text { suas tecnologias }\end{array}$} & Língua portuguesa \\
\hline & & Arte \\
\hline & & Espanhol \\
\hline & & Educação física \\
\hline & \multirow{4}{*}{$\begin{array}{c}\text { Ciências humanas e suas } \\
\text { tecnologias }\end{array}$} & História \\
\hline & & Geografia \\
\hline & & Filosofia \\
\hline & & Sociologia \\
\hline & \multirow{4}{*}{$\begin{array}{c}\text { Ciências da natureza, } \\
\text { matemática e suas } \\
\text { tecnologias }\end{array}$} & Biologia \\
\hline & & Química \\
\hline & & Física \\
\hline & & Matemática \\
\hline & Diversificada & Metodologia da Pesquisa Científica \\
\hline
\end{tabular}




\begin{tabular}{|c|c|}
\hline & Informática \\
\hline \multirow{18}{*}{ Formação profissional } & Empreendedorismo \\
\hline & Fundamentos de administração \\
\hline & Teoria geral da administração \\
\hline & Direito administrativo \\
\hline & Contabilidade I \\
\hline & Contabilidade II \\
\hline & Introdução à economia \\
\hline & Introdução ao marketing \\
\hline & Economia brasileira \\
\hline & Matemática financeira \\
\hline & Administração de vendas \\
\hline & Planejamento estratégico \\
\hline & Gestão de pessoas \\
\hline & Administração financeira \\
\hline & Ética \\
\hline & Noções de direito do trabalho \\
\hline & Informática aplicada à administração \\
\hline & Português instrumental \\
\hline
\end{tabular}

Observa-se que tanto os componentes curriculares da base nacional comum quanto da formação profissional são pertinentes para o desenvolvimento do projeto INCUTEC, pois as alunas tem acesso às diversas áreas do conhecimento o que favorece a formação integral das mesmas.

É possível observar que a coordenadora pretende propiciar uma formação mais ampla aos alunos partícipes do projeto, pois demonstra buscar ultrapassar o conhecimento puramente teórico, para aliar este conhecimento à prática e assim tornar estes jovens capazes de atuar diretamente na realidade local, proporcionando-Ihes a relação ação-reflexão. Em leitura ao projeto INCUTEC, percebe-se ainda, que Barros (2012) se preocupa com a compreensão por parte dos alunos de que o trabalho não se reduz à mercadoria força de trabalho, nesse sentido, vem dizer que:

O Projeto Incubadora de Serviços como Instrumento de Geração de Emprego e Renda vai ao encontro tanto de iniciativas espontâneas de divulgar o empreendedorismo juvenil como instrumento capaz de criar postos de trabalho, propondo soluções que ultrapassem os limites do assalariamento ou da venda da força de trabalho, mas concretize formas autônomas, porém sustentáveis e inovadoras de organização do trabalho. 
Portanto, as ideias desta vão ao encontro do que enfoca Frigotto $(2010$, p.63) sobre o fato de que:

\begin{abstract}
A força de trabalho expressa sua centralidade ao se transformar em produtora de valores de troca, com o fim de gerar mais lucro ou mais valor para os capitalistas. O trabalho, então, de atividade produtora imediata de valores de uso para os trabalhadores, se reduz à mercadoria força de trabalho e tende a se confundir com emprego.
\end{abstract}

No questionário aplicado aos docentes das turmas de administração nas quais faziam parte as alunas participantes do projeto, fez-se a seguinte pergunta: Você percebeu alguma diferença antes e após participação no Projeto INCUTEC? E as respostas obtidas foram que se notou sim, certa mudança, as discentes mostraram-se mais responsáveis, interessadas e participativas em sala de aula como também mostraram bastante empenho durante o desenvolvimento do projeto. Um dos docentes frisou ainda que o fato da participação dessas alunas no INCUTEC despertou interesse nos demais colegas em participar do projeto em etapas posteriores.

Diante da resposta dos professores, observou-se que a participação das alunas no projeto foi de suma importância para suas formações, pois as mesmas demonstraram crescer tanto pessoalmente quanto profissionalmente.

Diante o exposto, percebe-se a relevância de engajar alunos em projetos de integração como este, pois leva o aluno a conhecer melhor sua realidade, vivenciar experiências voltadas ao mundo do trabalho, estimula a formação integral, como também enriquece sua formação profissional. Pode-se dizer que o projeto vai ao encontro do anseio por uma educação de qualidade social, visto que, nas palavras de Libâneo (2004, p.66) "escola com qualidade social significa a interrelação entre qualidade formal e política, é aquela baseada no conhecimento e na ampliação de capacidades cognitivas, operativas e sociais, com alto grau de inclusão".

Evidentemente não basta um projeto para tornar toda uma escola com qualidade social, outros fatores influenciam para dar esta conotação a uma instituição de ensino, no entanto, ressalta-se a positividade deste, enquanto iniciativa que pode promover e estimular a incorporação desta qualidade social na escola.

Com relação ao questionário aplicado às alunas, buscou-se identificar o que o projeto proporcionou a elas, desta forma, as alunas foram questionadas sobre conhecimentos necessários durante todo o desenvolvimento do projeto e sua relação com a sala de aula, as percepções destas com relação ao projeto INCUTEC e o que esta experiência as proporcionou.

É possível notar em todas as respostas dadas pelas discentes que o projeto INCUTEC proporcionou às alunas uma visão ampla da realidade local, aliando as visitas às empresas com os conhecimentos da sala de aula e os momentos de discussão sobre os dados obtidos no projeto junto à coordenadora.

Observando estas respostas, é possível dizer que as alunas conseguiram conhecer a realidade, refletir sobre esta através dos conhecimentos adquiridos e apresentar possíveis soluções aos problemas encontrados nas empresas da cidade de Buriticupu. Isto demonstra a capacidade crítico-reflexiva que o projeto proporcionou a estas alunas. 
Ao final desta primeira etapa do projeto INCUTEC, foram convidados os representantes das empresas visitadas para a apresentação do diagnóstico final realizado pelas alunas, nesta ocasião, o número de empresários presentes foi pequeno, o que vem a confirmar, os resultados do relatório final do projeto INCUTEC, onde consta que estes não recepcionaram de forma adequada as alunas durante o processo de entrevista e evidenciaram o desinteresse em contratar pessoas qualificadas a desempenhar o trabalho.

\section{CONSIDERAÇÕES FINAIS}

Neste trabalho buscou-se analisar as possíveis contribuições do projeto de extensão INCUTEC no Curso Técnico em Administração integrado ao Ensino Médio do IFMA Campus Buriticupu, enquanto uma experiência de prática integradora. Ao fim desta pesquisa podemos pontuar algumas considerações entre os objetivos deste projeto de extensão e suas reais implicações no contexto da educação profissional.

A ideia de educação profissional integrada ao ensino médio supõe que esta "integração" irá superar as divisões entre trabalho manual e trabalho intelectual historicamente imposta, posto que, teoricamente, integrar a educação básica à educação profissional significaria compreender o trabalho como princípio educativo, conforme exemplifica Frigotto (2010). Logo, os jovens deveriam entender o trabalho como um direito e um dever, pois a origem do mesmo advém de uma necessidade de todo ser humano, uma questão de sobrevivência, mas explorar uns aos outros através do trabalho não o é. Esta exploração na verdade é uma configuração de uma relação de poder, de desigualdades, de relações sociais, de tornar-se um mamífero de luxo, como expressa Gramsci.

Percebe-se, no entanto, que apesar do avanço em ofertar o ensino médio integrado ao ensino profissional, há ainda muitos desafios a superar, pois conforme Frigotto, Ciavatta, e Ramos (2010, p.74):

\footnotetext{
O ensino médio integrado ao ensino técnico, conquanto seja uma condição social e historicamente necessária para a construção do ensino médio unitário e politécnico, não se confunde totalmente com ele porque a conjuntura do real assim não o permite. Não obstante, por conter os elementos de uma educação politécnica, contém também os germens de sua construção.
}

Assim, por mais que no âmbito da educação, se busque uma forma de transformar a realidade, através de uma formação qualitativa, isto, por si só não basta, visto que seria também necessária a transformação social, a superação das desigualdades.

Pode-se citar o projeto INCUTEC como um exemplo desta tentativa de transformação, posto que ao mesmo tempo em que é um instrumento de geração de renda e emprego, o projeto proporcionou aos jovens partícipes uma visão mais ampla das relações de trabalho e suas consequentes relações sociais, pois atuaram enquanto mediadores deste processo.

Percebeu-se que o projeto INCUTEC superou os objetivos propostos, configurou-se uma prática integradora, pois acabou por exigir no desenvolvimento de suas atividades que os jovens participantes do projeto, tivessem um entendimento crítico de como funciona a sociedade e suas relações sociais, bem como, compreendessem a essência do trabalho, enquanto algo natural da necessidade do ser humano como parte da natureza. 
Assim, um pequeno projeto em um município do interior do Maranhão, conseguiu com uma parcela dos jovens estudantes do Curso Técnico em Administração do IFMA Campus Buriticupu, proporcionar uma prática integradora, que possibilitou a integração dos conhecimentos da educação básica e da educação profissional. Há que se pontuar, que o projeto, ora citado, foi pesquisado em sua fase inicial, mas a proposta da autora do projeto, professora Andrea Barros, é de proporcionar a outros jovens a mesma experiência.

É evidente que a experiência de sucesso do projeto INCUTEC no IFMA Campus Buriticupu, não é a solução para toda e qualquer realidade, tampouco, atinge a perfeição, no entanto, é um exemplo de uma experiência que estimula positivamente àqueles que lutam constantemente por superar as desigualdades sociais, suas relações de poder e almejam uma educação unitária.

\section{REFERÊNCIAS BIBLIOGRÁFICAS}

1. ARAUJO, R.A.S. MELO, M.A. A prática como componente curricular na Universidade Federal do Maranhão: implicações no Curso de Licenciatura em Educação. In: anais do II Congresso Internacional de Formação Profissional em Educação Física e VI Seminário de Estudos e Pesquisas em Formação Profissional no Campo da Educação Física. Florianópolis: [s.n.], 2012, p.515-532.

2. BARROS, Andrea L. Projeto Incubadora de Serviços como Instrumento de Geração de Emprego e Renda. Projeto Institucional do IFMA Campus Buriticupu, Buriticupu, 2008.

3. BRASIL. Lei n. 11.892 de 29 de dezembro de 2008. Lei que institui a Rede Federal de Educação Profissional, Científica e Tecnológica, cria os Institutos Federais de Educação, Ciência e Tecnologia, e dá outras providências. Brasília, DF, 2008.

4. CIAVATTA, M. A formação integrada: a escola e o trabalho como lugares de memória e de identidade. In: FRIGOTTO, G. CIAVATTA, M. RAMOS, M.(Orgs.) Ensino Médio Integrado: concepções e contradições. 2 ed. São Paulo: Cortez, 2010.

5. FRIGOTTO, G. Concepções e mudanças no mundo do trabalho e o ensino médio. In: FRIGOTTO, G. CIAVATTA, M. RAMOS, M.(Orgs.) Ensino Médio Integrado: concepções e contradições. 2 ed. São Paulo: Cortez, 2010.

6. IFMA. Projeto do curso técnico em administração integrado ao ensino médio. Projeto Institucional do IFMA Campus Buriticupu, Buriticupu, 2008.

7. KUENZER, Acácia Z. O ensino médio no plano nacional de educação 2001-2010: superando a década perdida? Educ. Soc., v. 31, n. 112, p. 851-873, jul/set. 2010.

8. LIBÂNEO, José C. Organização e Gestão da Escola: teoria e prática. 5a ed. Goiânia: Alternativa, 2004. 